
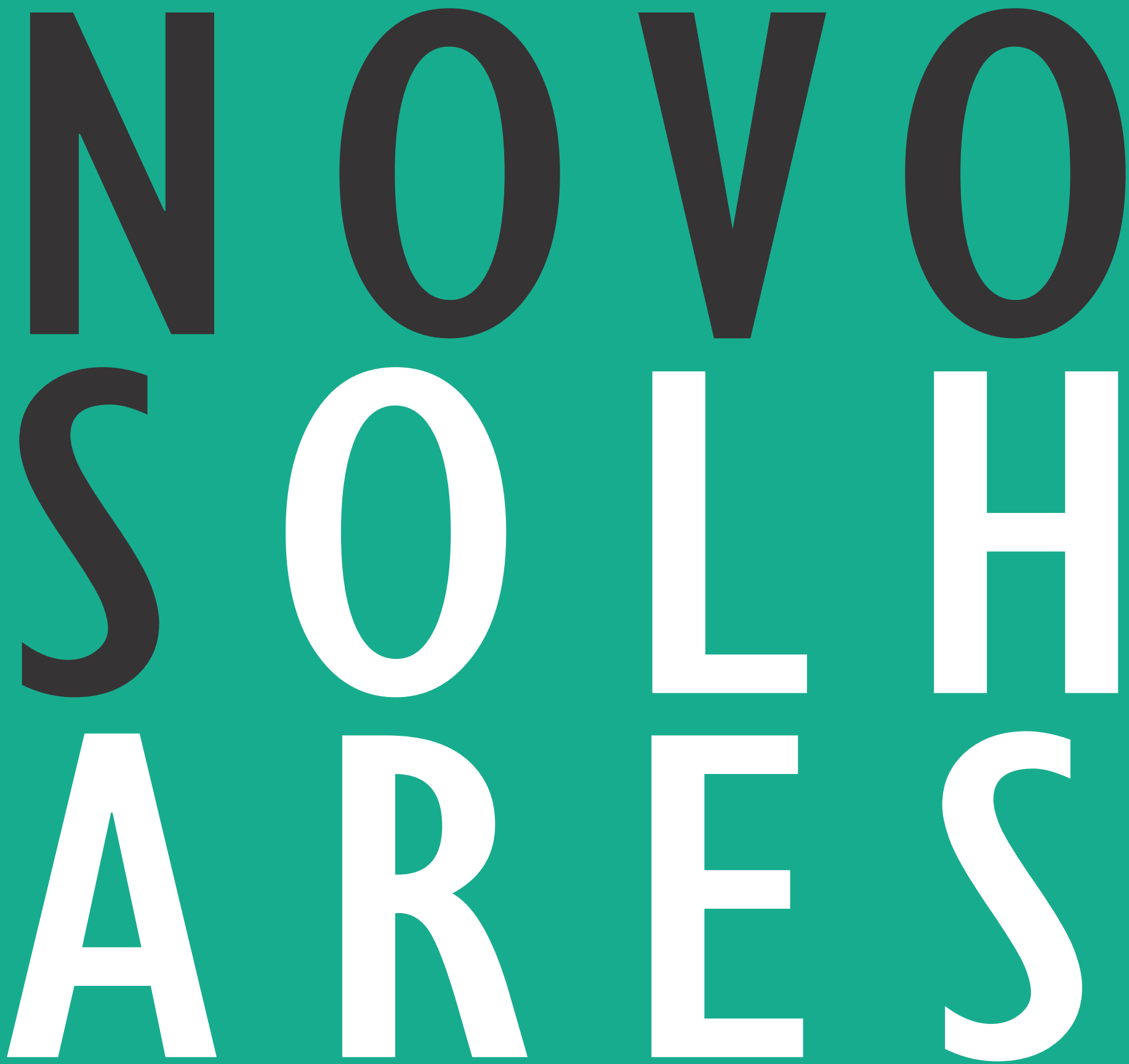

REVISTA DE ESTUDOS SOBRE PRÁTICAS DE RECEPÇÃO A PRODUTOS MIDIÁTICOS

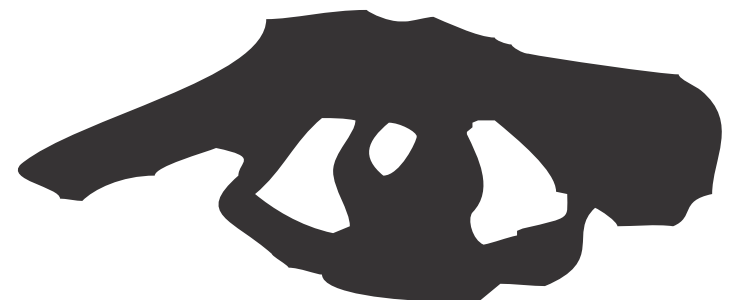

Volume I N. 2 


\section{Uma Nova}

Fase Para

Novos

Olhares

A partir de 2012, a Novos Olhares - Revista de Estudos Sobre Práticas de Recepção a Produtos Midiáticos, iniciou uma nova fase. A publicação foi criada em 1998 pelo Grupo de Estudos Sobre Práticas de Recepção a Produtos Mediáticos, coordenado pelo Prof. Mauro Wilton de Sousa, que se tornou seu editor. Até 2007, a revista teve 19 edições impressas, tornando-se uma das principais referências do país na área de estudos culturais. Em sua nova fase, ela passa a ser publicada exclusivamente em formato digital e passa a ser vinculada ao Programa de Pós-Graduação em Meios e Processos Audiovisuais (PPGMPA), bem como ao Departamento de Cinema, Rádio e TV (CTR) da Escola de Comunicações e Artes da Universidade de São Paulo. Além disso, o Prof. Eduardo Vicente passa a dividir com o Prof. Mauro Wilton de Sousa a função de editor da publicação, que teve o seu Conselho Editorial completamente renovado. O próprio ISSN da revista precisou ser alterado, passando de 1516-5981 (edição impressa) para 2238-7714 (edição eletrônica).

Outra modificação que poderá ser observada refere-se à numeração da revista: ela passou a seguir o formato volume/número e foi reiniciada. Assim, as duas edições de 2012 se tornaram os números 1 e 2 do Volume 1 . Mas é preciso ressaltar que isso não significa uma ruptura com a tradição, a história e a temática da revista. Ao contrário, ela continua comprometida com o fortalecimento do debate sobre a questão da recepção e das práticas no contexto da produção audiovisual. Também, por isso, todas as suas edições anteriores já foram disponibilizadas no portal da revista em formato digital.

Embora priorize os textos de professores-doutores, preferencialmente vinculados a programas de pós-graduação, a Novos Olhares aceita colaborações de alunos de pós, oferecendo espaço para a publicação de trabalhos de doutorandos, mestres, mestrandos e, em casos especiais, até mesmo de graduados. Assumimos essa decisão como uma forma de permitir a expressão de diferentes experiências e a ampliação dos espaços cada vez mais raros - para a publicação de textos de alunos. Assim, também nesse sentido, compreendemos a revista como um espaço para a expressão de "novos olhares".

Atenciosamente

Os editores 
Novos Olhares - ISSN 2238-7714

Revista de Estudos Sobre Práticas de Recepção a Produtos Midiáticos

Publicação semestral on line do Programa de Pós Graduação em Meios e Processos

Audiovisuais (PPGMPA) da ECA/USP

Vol.1 , n. 2 (20 Semestre de 2012)

Revista surgida em 1997 como publicação impressa com o ISSN 1516-5981. 0 formato eletrônico e a edição em volume anual com dois números foram adotados em 2012, ano em que a numeração da revista foi reiniciada. 


\section{Expediente}

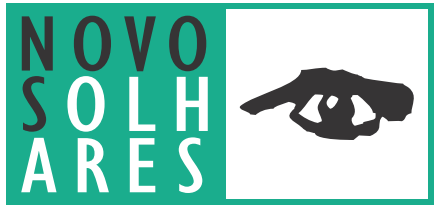

Revista de Estudos sobre Práticas de Recepção a Produtos Midiáticos: publicação semestral do Programa de Pós-Graduação em Meios e Processos Audiovisuais e do Departamento de Cinema, Rádio e Televisão da ECA-USP.

\section{ISSN 2238-7714}

Volume I - número 2 - 2 semestre de 2012

\section{Editores}

Eduardo Vicente - Universidade de São Paulo

Mauro Wilton de Sousa - Universidade de São Paulo

\section{Conselho Científico}

Claudia Lago - Universidade Anhembi Morumbi Eduardo Morettin - Universidade de São Paulo Elizabeth Saad - Universidade de São Paulo Fernando Resende - Universidade Federal Fluminense Gilberto Prado - Universidade de São Paulo Luiz Signates - Universidade Federal de Goiás Marilia Franco - Universidade de São Paulo Rosana Soares - Universidade de São Paulo Salwa Castelo-Branco - Universidade Nova de Lisboa

\section{Comissão Editorial}

Daniel Gambaro

Evaldo Piccini

Nivaldo Ferraz

Rafael Duarte Oliveira Venancio

Editoração Eletrônica e Projeto Gráfico

Lucas Siqueira Cesar

Normas para publicação e condições para o envio de colaborações poderão ser encontradas no site da revista (www.eca.usp.br/ novosolhares), que se reserva o direito de aceitar ou não as colaborações enviadas. As opiniões emitidas nessa publicação não expressam necessariamente a posição da revista.

\section{Revista Novos Olhares}

Departamento de Cinema, Rádio e TV - ECA Av. Prof. Lúcio Martins Rodrigues, 443, prédio 4 Cidade Universitária, São Paulo-SP CEP: 05508-900

e-mail: novosolhares@usp.br

\section{Sumário}

\author{
Uma Nova Fase Para Novos Olhares \\ 2
}

\author{
Apresentação \\ 6
}

Pictogramas na comunicação de espaços públicos: reflexões sobre o processo do design Guilherme Ranoya, Milton Raposo, Silvio Koiti Sato e Sandra Souza

7

Avaliação dos Modelos de Governança da Cadeia da Indústria Fonográfica Pré e Pós-Internet

Thiago Lobão de Almeida e Davi Noboru Nakano

22

\begin{abstract}
A cultura de participação do público na produção do noticiário provoca mudanças nos critérios de noticiabilidade
\end{abstract}

Beatriz Dornelles e Paula Renata Minozzo

32

Publicidade, Entretenimento e Consumo: Aspectos Interativos

Christina Maria Pedrazza Sêga

41 
Interdições Imaginárias

Andrea Limberto

50

Possibilidades criativas da reportagem radiofônica

Nivaldo Ferraz

62

"Pra Frente Brasil", "Independência ou Morte" e o uso de musica e cinema como propaganda oficial: engajamento ou encampação?

Evaldo Piccino

74

Os Primórdios dos Discos Comerciais da Música Tradicional Brasileira Roberto Nunes Corrêa

84

Trilha Sonora: o cinema e seus sons Bernardo Marquez Alves 90

Do silencioso ao sonoro 3D - breve reflexão sobre público e mercado

Rosana Stefanoni Iwamizu

96 